\title{
UCLA
}

Mester

Title

Tú Reías

Permalink

https://escholarship.org/uc/item/4m97v5f2

Journal

Mester, 15(2)

Author

Perdigó, Luisa M.

Publication Date

1986

DOI

10.5070/M3152013799

Copyright Information

Copyright 1986 by the author(s). All rights reserved unless otherwise indicated. Contact the author(s) for any necessary permissions. Learn more at https://escholarship.org/terms

Peer reviewed 


\section{TÚ REÍAS}

Ya no estabas por más que te buscamos

Ya eras en la nada

Todo eran piedras

las unas tras las otras en recta fila dada

Y si rezamos de prisa

fue por no saber qué más

hacer

ante tu presencia en calma

Después nos fuimos, y ya no

pudimos verte ni oírte más entre la grama Pero yo te supe entre nosotros, latente como siempre en el aire límpido, fresco de la mañana

Reposabas

Estaba el cielo vestido

con sus más azules galas

y tú reías

eternamente

plácidamente entre sus alas.

Luisa M. Perdigó

15 de enero de 1985 